\title{
Competencies For Managing Unstructured Information In The Knowledge Evolution: A Rocky Mountain Regional Study Of CEO Perspectives
}

Gary R. Schornack, (E-mail: gschorna@ carbon.cudenver.edu), University of Colorado at Denver Charles E. Beck, (E-mail: cbeck@uccs.edu), University of Colorado at Colorado Springs

\begin{abstract}
For modern managers to remain competitive in the information age, they must capture and leverage knowledge. An Integrative Model of Knowledge Management can provide a way of visualizing the interrelated elements for an effective knowledge-management system. This original model builds on a Rhetorical Process Model of Communication, which considers both objective and subjective elements within human communication. In addition, it clarifies the purpose and method elements at the center for any effective knowledge system. Knowledge builds relationships among people who are willing to share what they know for the good of the organization. Organizations that fully develop the human potential of their people grow in economic value. Within the theoretical dimensions of the Model, this study incorporates the preliminary findings from interviews with 429 executives in the Rocky Mountain region.
\end{abstract}

\subsection{Introduction}

o survive in the Information Age, businesses must understand how knowledge works within their organizations, and they must manage their information needs. As Davis indicates, "companies are having to develop new systems and cultures to encourage real knowledge transfer (1998, p. 27). Intellectual assets have now achieved an equal significance with the tangible assets of a company, resulting in managers beginning to grapple with the issue. However, managers recognize that they are working in an unfamiliar area. As one of the pioneers in the field describes the issue, "Over time, the concept of KM developed into something rich in potential that enhances an organization's overall value by leveraging and expanding intellectual assets (Duffy, 2001).

In particular, organizations do not use over $80 \%$ of the information collected (Calo, 2002). This paper proposes an Integrative Model of Knowledge Management as a way to unify the field. It begins by clarifying the underlying base of a new model, Rhetorical Process Model of Communication. It then elaborates the elements of the Preliminary Model: the input status and assumptions; the purpose elements of intention and audiences; the method elements of technical tools and human processes; the chaos creativity that integrates the elements; the output products and interpretations; and system feedback.

Readers with comments or questions are encouraged to contact the authors via email. 
For this relatively new field, the proposed Integrative Model identifies the elements needed to manage knowledge. The model builds on a systems-based model of communication, the Rhetorical Process Model. Figure 1 displays the Rhetorical Process Model, the basis for our Preliminary Model.

Figure 1: Rhetorical Process Model

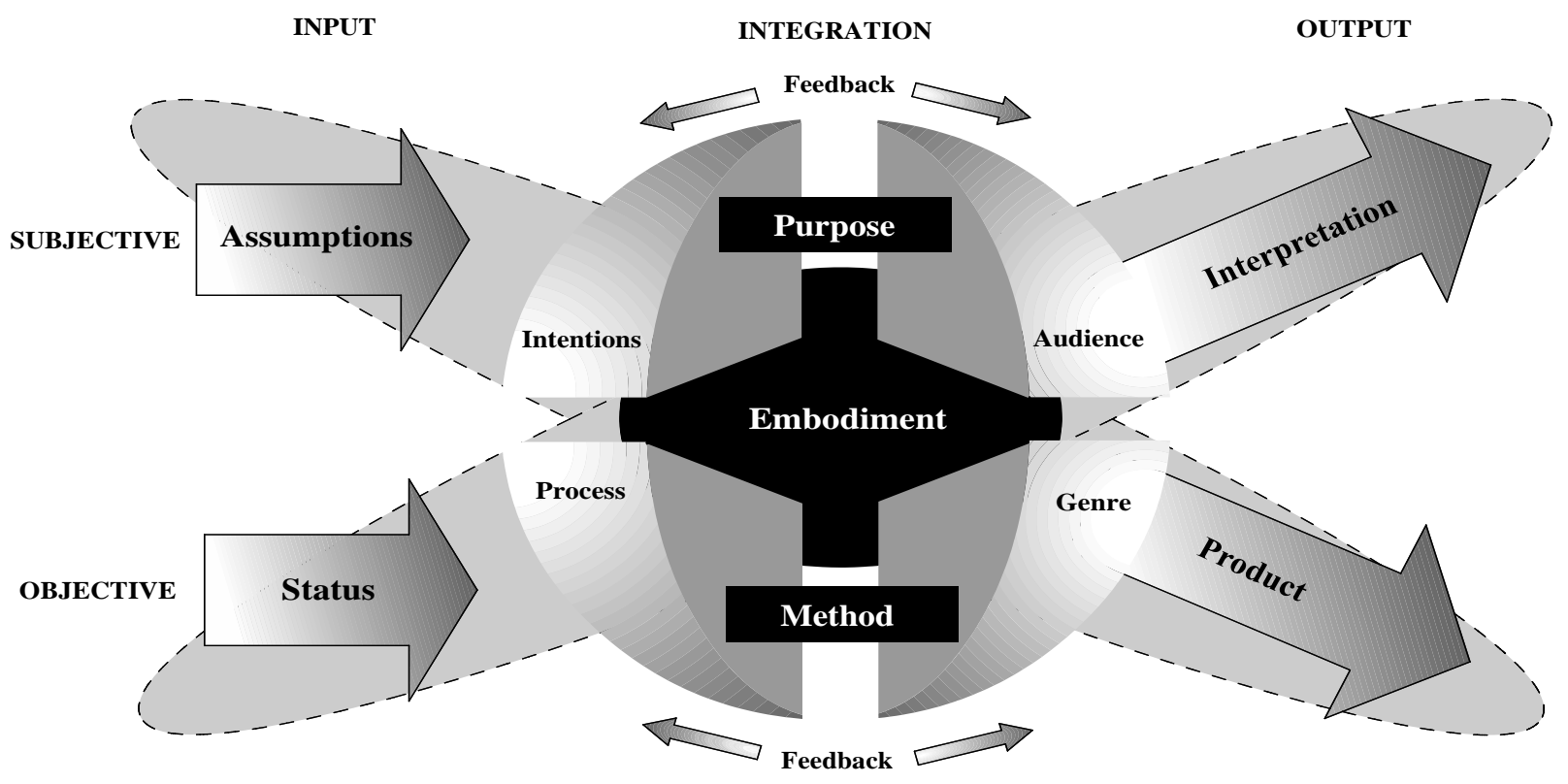

Adapted from: C. Beck, Management Communication (Prentice-Hall, 1999) p. 32.

The Rhetorical Process Model builds on a simple system consisting of inputs, an integration center, and outputs. The rhetorical process takes this simple system and divides it in two ways. The horizontal division separates the objective in the subjective parts of the process. Additionally, the integration section is further divided in half, creating four elements within the central integration. The inputs to this process include the status and the assumptions. The integration begins at the top center of the model, with the purpose elements of intentions and audiences. The integration continues with the bottom elements of methods, which include the machine tools and the human processes involved in knowledge management. These four elements of integration do not occur in a linear fashion; rather, they interact, labeled here as creativity/chaos. The term chaos does not mean confusion but reflects the aspects of chaos theory which draws patterns of disparate elements. The outputs of the model include both the product and the interpretation. While the products are the objective and observed outputs, the interpretation is more subjective open to a broader view of the same products. The final aspect of the model is feedback, which can occur throughout the entire model rather than just from the outputs back to the inputs. The Integrative Model takes the elements of this rhetorical process and elaborates those aspects that apply to knowledge management, as shown in Figure 2.

The model is epistemic, serving as an approach "which examines knowledge from a human, cognitive, and even philosophical view" (Pemberton, 1999, p. 60). The critical integration elements of the model include a clarification of purpose (intentions and audience) and method (technical tools and human processes). These interactive elements embody the output products, which are subject to multiple interpretations. Feedback within the model permits the revision and refinement of knowledge and information.

3.0 Inputs 
The model begins on the left side with inputs, including the objective status and subjective assumptions. The inputs, the given elements of the system, tend to remain rather stable over time. When they do change, they tend to do so rather slowly.

Figure 2: The Integrative Model of Knowledge Management

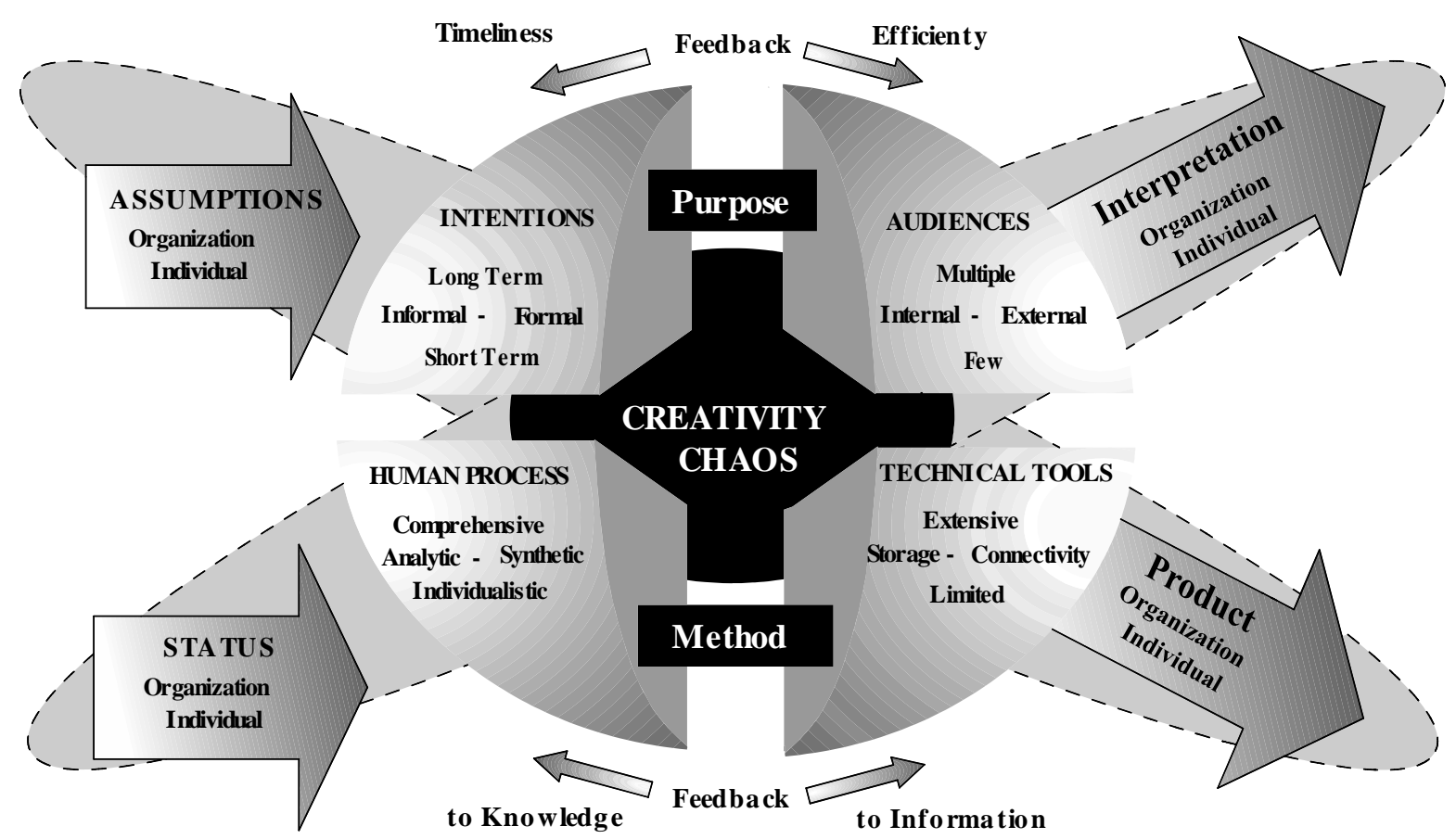

\subsection{Status}

The model begins in the lower left hand corner, with the overall category, status. Status reflects the objective elements in any human communication encounter, elements which may be verified independently. Status consists of two parts, the individual and the organization. All communication begins with the individual, whether that person is a corporate executive or a beginning clerical assistant. For the individual, the status elements include both the person's background (education, experience, gender, training), and the role in the organization (job title, description, and specific responsibilities).

Because the knowledge management requirements vary depending on the type of organization, the organization itself is a significant status element. Within the model, organization may refer to the overall company or a single department. Among the many ways to classify an organization, two significant elements include size and diversity. The size of an organization indicates the number of people who interact or potentially interact, thus representing the number who may need a given type of information or knowledge. The diversity of an organization includes the range of backgrounds, types of positions, background knowledge requirements, and nature of the specific tasks completed. To meet the coming needs, organizations are focusing on data warehousing, data mining, and data management, along with network integration and security ("Consulting's Next Big Thing", 2000). Organizations have even begun hiring chief knowledge officers (CKO) to oversee knowledge and learning (DeTienne et al., 2001). Unfortunately for now, "with the specialized exception of units whose entire business is 
knowledge management, there's no obvious, proven model to follow" (Angus, 1998). The function of the new CKO position is to design, develop, and coordinate new learning initiatives for the organization.

\subsection{Assumptions}

Assumptions, the subjective aspects of inputs within any knowledge management system, also consist of both individual and organizational elements. With individuals, assumptions usually consist of underlying values and ethical standards. People may have an explicit set of values or an implicit way of acting which they follow without much conscious thought. The assumptions also include the style in which someone completes a task: informal or formal, deductive or inductive, right-brained or left-brained, up-tight or laid-back. In the perspective of Zuckerman and Buell, "Remember that it's humans, not technology, that drive a company and the information management efforts that are crucial to success" (1998).

Beyond the individual, assumptions also apply to the organization, particularly in terms of culture and climate. Many assumptions may exist on how to capture and leverage the knowledge assets. The organizational culture reflects the way the organization functions, ranging from the family or team styles to dictatorship or even anarchy. The culture may determine whether informal or formal norms will guide activities, including such issues as communication processes and dress codes. As Safdie and Edwards indicate, "Knowledge management is a culture, not a system" (1998). The assumptions also include the climate of the organization. An open climate fosters the sense of creativity and innovation among individuals, where people feel free to ask questions, suggest changes, and brainstorm alternatives. In contrast, a closed or defensive climate stifles communication and reduces interaction, as people spend psychic energy protecting themselves from real or perceived threats if they step out of bounds. KM implementation requires an acute awareness of the organization's assumptions. According to DeTienne et al., the basis of KM involves helping employees share their knowledge; however, the organization's culture presents a significant obstacle in the implementation. As a result, the effort in implementing KM involves "changing organizational culture and people's work habits" (2001). Appointing a full-time CKO may help drive "the development of a knowledge culture" (Oxbrow, 2000). Many knowledge management systems produce a lot of data with little understanding of its significance and what should be done as a result of the new information.

\subsection{Purpose}

Building on inputs, all human systems begin with a sense of purpose, which clarifies the specific intentions of the activity and the audience or audiences involved. For a company, the knowledge management strategy should reflect its competitive strategy: how it creates value for customers, how that value supports an economic model, and how the company's people deliver on the value and the economics (Hansen et al., 1999). Within the knowledge management model, the elements of intention and audience divide into two-dimensional grids that focus the discussion.

\subsection{Intentions}

The intention element focuses on the extent of the knowledge need and the time frame for the final product. The extent ranges from informal to formal, and the time frame can either be short-term or long-term. Do we need just a single data point or do we need a synthesis of trends? Are we answering a simple question for a client or preparing a long-term strategy for action? Will a quick response fill the need or must we test and verify before creating our recommendations? Is our purpose one-time or do we envision a long-term commitment to another? The type of information sought will vary depending on the intended use of that information. Table 1 outlines the intention focus based on time frame (short- or long-term) and the degree of formality (formal or informal).

Knowledge management began with a recognition that consultants often developed significant ideas for specific clients, but did not always apply the same concepts in other areas (Duffy, 2000). Internally, organizations have begun to realize that an organization's collective knowledge is both immeasurable and priceless; knowledge results in a "tapping into databases, files, manuals, and most importantly, employees' brains to retrieve knowledge out of whatever receptacle in which it hides and putting it into the hands of those who could most benefit from it" 


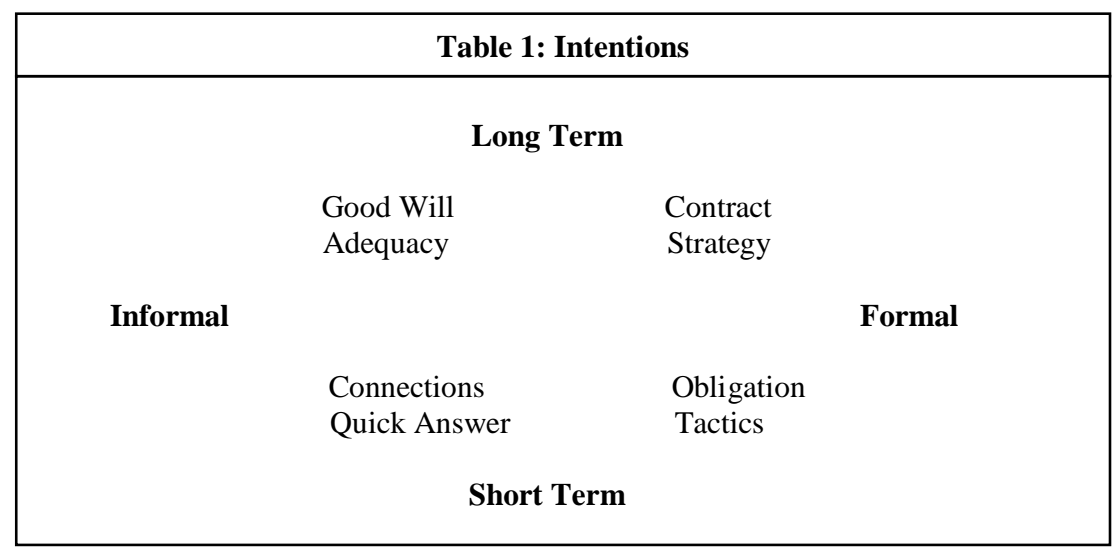

(DeTienne et al., 2001). To become effective, however, a company must begin with a clear cut, well-thought-out strategy for knowledge management (Clark and Poruban, 2001). The knowledge management function becomes catalyst for the entire organization: "to develop strategies, establish standards and procedures, stimulate change and new initiatives, and embed the desired culture, working practices, and behaviors into the organization" (Oxbrow, 2000).

Based on 429 interviews with top level managers, senior executives, and CEOs in the Metro Denver area, the KM approach tends toward the formal structure rather than informal structure by a three-to-one margin, as shown in Table 2.

\begin{tabular}{|lcc|}
\hline & Table 2: Intention Formality \\
\hline Formal & 318 & $74.1 \%$ \\
Informal & 111 & $25.9 \%$ \\
\hline Total & 429 & $100 \%$ \\
\hline
\end{tabular}

\subsection{Audiences}

The audience element clarifies who needs the information based on direction and size. Is the use internal or external to the organization? Will many or few people need the information? Will the information serve just a few colleagues and myself, or must I consider the wider needs of supervisors, contract administrators, and customers? Table 3 identifies the dimensions of audiences as internal or external and as many or few.

According to Morrison and Mezentseff, managers must replace an authoritarian relationship with learning relationships, with the leader as a coordinator: "the leader is not at the top of the organization; he is in the midst. He is not giving orders; he is not formulating policies; he is not controlling. He is coordinating" (Morrison and Mezentseff, 1997). The needs may change if we focus on those external to the organization, ranging from a single user or a narrow market niche to national and international users or government regulators. The area of customer relations management captures transaction information to create detailed pictures of individual customers (Sullivan, 2001). Having the knowledge and ability to learn is still one of the best predictors of advancement in the workplace. 


\begin{tabular}{|c|c|}
\hline \multicolumn{2}{|c|}{ Table 3: Audiences } \\
\hline \multicolumn{2}{|c|}{ Multiple } \\
\hline $\begin{array}{l}\text { Organization } \\
\text { Supervisors }\end{array}$ & $\begin{array}{l}\text { International } \\
\text { National }\end{array}$ \\
\hline Internal & External \\
\hline $\begin{array}{l}\text { Colleagues } \\
\text { Self }\end{array}$ & $\begin{array}{l}\text { Target Market } \\
\text { Specific User }\end{array}$ \\
\hline \multicolumn{2}{|c|}{ Few } \\
\hline
\end{tabular}

The internal audience, however, is the dominant focus in knowledge management. The information age requires a major change in understanding of the workplace: "Workplaces must be understood as social settings of negotiated meanings in which knowledge becomes inextricably and idiosyncratically embedded within the particular activity system that is generating these meanings" (Porac and Glynn, 1999). Employers must ensure that workers "have the fundamental skills to deal with whatever knowledge management technology and processes are adopted by the company" (Oman, 2001). Ensuring proper skills means keeping employees trained (Steinberg, 2001) and recognizing the value of intellectual capital. While most organizations focus on explicit knowledge, more significant is capturing the tacit knowledge - personal knowledge possessed by an employee that may be difficult to express or communicate to others (Erickson and Rothberg, 2000). The survey of 429 Denver executives indicates an internal focus with an audience of few rather than many, as shown in Table 4.

\begin{tabular}{|llrr|}
\hline \multicolumn{4}{|c|}{ Table 4: Audience Size and Direction } \\
\hline \multirow{2}{*}{ Audience Size } & Few & 340 & $79.3 \%$ \\
& Many & 89 & $20.7 \%$ \\
\hline & Total & 429 & $100 \%$ \\
\hline \multirow{2}{*}{ Audience Direction } & External & 64 & $14.9 \%$ \\
& Internal & 365 & $85.1 \%$ \\
\hline & Total & 429 & $100 \%$ \\
\hline
\end{tabular}

\subsection{Method}

The method elements of the Integrative Model recognize that "knowledge management is not a technology, though it utilizes technology" (Safdie and Edwards, 1998). Thus method recognizes the two major components for processing information: through the use of technical tools and through the human thought process. The objective is to provide just-in-time information.

\subsection{Technical Tools}

America has led the move into the information age through expanding use of technology to facilitate information processing. Over the last few years, a slew of new tools has emerged to slay the information dragon 
(Greengard, 2000). The various tools range from fast computer chips and expanded memory for personal and mainframe computers, to the changing technology for distance communication using phone lines, fiber-optic cable, and satellite transmissions. Some of the knowledge management tools also includes significant collaborative features (Waltner, 2000), along with the increased capability to allow employees to work remotely, anywhere in the world, while still having access to the information via the Web (Mitchell, 2001). Recent efforts enable employees of large enterprises to share knowledge and information, thereby avoiding the loss of data "socked away on the hard drive of some forgotten workstation" (Black, 2001). The challenge is to demystify the technology issues.

For technical tools, the model considers the capacity ranges from extensive to specific or limited. The characteristics also include the storage capacity and the degree of connectivity to existing and new systems. Although the electronic systems predominate with click and drag systems, the model recognizes even the manual storage in notebooks and files, as well as the use of conversation among the many options in connecting to obtain knowledge. Extensive and limited technical tools are shown in Table 5.

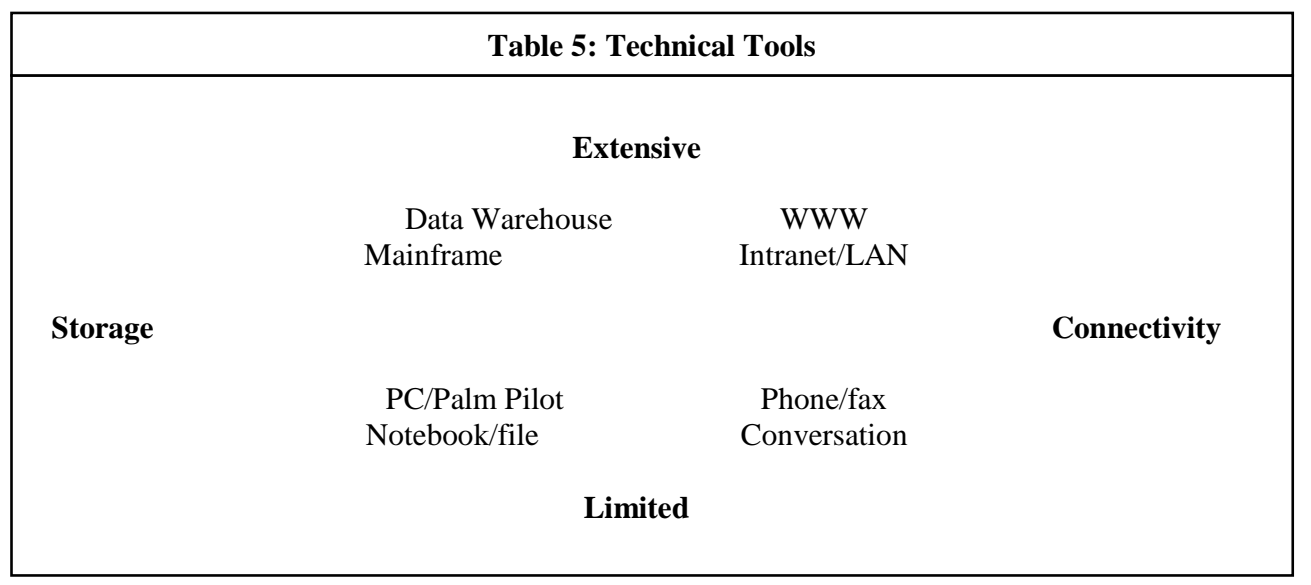

The technical tools are critical but not sufficient for knowledge management systems. For example, Hewlett-Packard designed an Electronic Sales Partner designed to allow salespeople to quickly access documents and literature to help solve customer business problems (DeTienne, et al., 2001). UPS improved performance and efficiency by first building a world-class e-business infrastructure (Perna, 2001); but their structure supported the need to know for customers and support personnel. The technology, regardless of its degree of complexity, must be integrated into the organizational need. Part of the focus requires focusing more time and attention on filtering (Boomer, 2001), thus ensuring timeliness without overload. According to Deveau, "There is a lot of information coming in and it's a matter of understanding what you need to capture. It takes data mining and test analyst tools to provide insight into patterns and behavior" (Deveau, 2002). Duffy outlines a process to move from data records to information, as shown in Table 6.

The technology tools and techniques we choose to look at problems and situations tend to influence what we find. Extensive training on the technical tools for all levels of the organization isn't merely a necessary evil but a crucial business strategy.

\subsection{Human Processes}

The focus on the human processes begins with practical interests. Businesses depend on their staffs "working together and communicating effectively and creatively" so they can respond to the market (Abell, 2000). Such coordination must be timely, since "Nothing is worse than searching and not finding the answers needed to problem-solve in a hurry" (Serva, 2002). Finding answers requires tapping the tacit knowledge, the "know-how" of 


\begin{tabular}{|l|}
\hline \multicolumn{2}{|c|}{ Table 6: Managing Information } \\
* determining whether or not documents or objects or records \\
* defining all records' physical locations and preventing unauthorized access \\
* establishing appropriate timeframes for transferring records from one status \\
(active, inactive, archive) or location or another \\
* developing and managing policies that govern records destruction \\
* providing the framework for consolidating organizational knowledge \\
* facilitating location and sharing of previously inaccessible knowledge \\
* codifying knowledge whenever possible, providing pointers to tacit knowledge \\
* encouraging collaborative innovation and promotion of existing knowledge \\
as a foundation for new ideas
\end{tabular}

employees that is often not written down (Coleman, 2002). Focusing on the human processes requires understanding "how and why people search for information, how they evaluate that information, when they stop looking, and how they use the information they have found" (Myburg, 2002).

Within the integrative model, the human processes include human cognition, as viewed by philosophy (epistemology), psychology, and popular culture. Zuckerman and Buell identify some of the key aspects of this human process: "Analyzing means knowing how to ask the right questions. Breaking down information means knowing how to organize information and knowledge, and that requires human judgment, which the most sophisticated computerized search engines can't replace" (1998). In the creation of knowledge, cognitive behavior ranges from specific, unique situations to the most comprehensive integration of information. Theory and wisdom comprise the more comprehensive cognitive processes, whereas acquaintance with a specific event or a serendipitous encounter forms the more individualistic. The horizontal elements in this matrix are the analytic and synthetic approaches to knowledge. This dichotomy may also appear under various alternate labels that characterize the same phenomena: left-brain and right brain; classical and romantic; yin and yang; animus and anima; deductive and inductive. As with the other elements in the model, neither approach is "better" than the other; rather, they represent alternate ways of combining ideas to reach knowledge or understanding. Table 7 outlines the parameters of these human processes.

The human processes in the model identify the range of end users get information either by browsing the organized information or by creating structured reports (Angus, 1998). In moving from individual usage to the wider organization, knowledge management requires a comprehensive examination of the organization, "analyzing business processes and information flows and how they can support one another" (Myburg, 2002). Technological tools and methods change rapidly and we can no longer rely solely on our experience. Experience quickly goes out of date.

\subsection{Chaos-Creativity}

Chaos describes a complex, unpredictable, and orderly disorder in which patterns of behavior unfold in irregular but similar forms. In chaotic systems, order emerges. Structure evolves. Life is a recognizable pattern within infinite diversity [Tetenbaum]. 


\begin{tabular}{|c|c|c|c|}
\hline \multicolumn{4}{|c|}{ Table 7: Human Processes } \\
\hline \multicolumn{3}{|c|}{ Comprehensive } & \\
\hline \multirow{5}{*}{ Analytic } & Theory & Wisdom & \\
\hline & Explanation & Imagination & \\
\hline & & & Synthetic \\
\hline & $\begin{array}{l}\text { Description } \\
\text { Acquaintance }\end{array}$ & Intuition & \\
\hline & & & \\
\hline
\end{tabular}

The center of the model represents the embodiment of the interaction among the purpose and method elements of the system. More specifically, the four basic elements of intentions, audiences, tools, and process do not have a linear relationship. As people approach a knowledge event, they may move among the categories: they may start with a preliminary idea of intentions and audience; but as they apply their cognitive skills and use different media to meet the needs, they change the parameters and rethink the approach, thus the continual interaction of the elements. In one view, "the process of creating knowledge is a spiral. It starts with people sharing their internal knowledge by socializing with others or by capturing it in digital or analog form. Other people then internalize the shared knowledge, and that process creates new knowledge inside them. Those people then share their new knowledge, and the process begins again" (Hibbard, 1997).

The terms chaos and creativity attempt to capture this interaction. Creativity involves drawing connections in a new way, a process that cannot be captured as a single event but the result of the interaction of the elements of purpose and method. Chaos is a richly ambiguous term: at the most popular level it represents an absolute lack of order; on the scientific level, chaos represents the way in which variations and patterns emerge within seemingly random phenomena. Thus the term chaos itself represents the range of knowledge integration from absolute dispersion to absolute integration. The Chaos-Creativity in knowledge management forms a five stage interactive process, as described in Table 8.

\begin{tabular}{|l|}
\hline Table 8: Creating Explicit Knowledge \\
\hline 1. Chart the terrain \\
2. Find the "ore" \\
3. Mine and refine the ore \\
4. Produce a finished product \\
5. Deliver end products \\
\hline
\end{tabular}

\subsection{Outputs}

The outputs of the Integrative Model include the objective product and the subjective interpretation. As with the inputs, the outputs divide among both individual and organizational characteristics. Organizational progress occurs when "knowledge moves from the domain of the individual to that of the organization" (Gore and Gore, 1999). 


\subsection{Product}

The products are objective, observable phenomena. For the individual, the output includes knowledge the main focus of the entire model - as well as solutions to perceived needs. Knowledge happens within individuals, but knowledge is not just something for its own sake; rather, it is part of a solution to a problem or inputs to action. For the organization, the output is information that serves an organizational need, as well as the dissemination of that information. The actual dissemination will involve the various technical tools discussed earlier. Organizations tend to rely on intranets to maximize information flow (Ojala, 2002). According to de Stricker, information content tends to focus on three centers in an organization (de Stricker, 2000):

- $\quad$ learning and training

- $\quad$ market and business data, research, and intelligence

- $\quad$ corporate or technical information centers

Ultimately, businesses hope to leverage their knowledge to achieve higher profits at lower expense (DeTienne et al., 2001). A measure of output is to examine how well the information met the need in a simple and the shortest way possible. Many organizations now reward for doing the opposite.

\subsection{Interpretation}

The output products are open to subjective interpretation by oneself or anyone else. Furthermore, people may have multiple and even incompatible interpretations. For the individual, the more relevant characteristics of the interpretation is the usability of the knowledge or information, as well as its simplicity. How well the information met the need, and did so in the easiest way possible are measurements of interpretation. According to Erickson and Rothberg, "The key concepts in knowledge management revolve around the collection and dispersion of knowledge" throughout the organization, "from end-customer to early stage supplier," with free sharing of information (2000). 0 Properly managing information saves both time and money (Serva, 2002).

Some preliminary findings from interviews with executives found mixed reaction to the usability of knowledge. Table 9 provides representative comments on positive usability, while Table 10 provides indicators of negative usability.

While knowledge management may seem to be the solution to information woes, the focus on technology in most knowledge management programs has only contributed to the problem. The key is how people deal with information, in a way that does not produce overload (Oman, 2001). At the other end of the spectrum, for integrated knowledge management throughout the organization, "Getting senior management to use the system that they themselves mandated can be a challenge" (Sumner-Smith, 2000). There is a great difference between wishing for integrated performance and managing performance in organizations. What is needed is a priority and commitment to manage a focused direction on the activities throughout the entire organization.

\subsection{Feedback}

A system is not complete without feedback that permits change throughout the system. In the Integrative Model, feedback from the product itself predominantly involves the development of new knowledge or information within both the individual and organization. Simplistically representing this feedback, knowledge returns to the human process and information to the technical tools. From the interpretation, feedback concerns the timeliness of the information and its efficiency in meeting both individual and organizational needs. While these two flows of feedback dominate, the model also recognizes that feedback may impact the inputs to the process. The objective inputs tend to change less frequently, since these are the "givens" within the overall process. However, the subjective inputs or assumptions may change as the result of new knowledge or information. Although assumptions by their very nature are the unquestioned ways of acting, feedback may change assumptions both within individuals and organizations. 


\title{
Table 9: Positive Responses to Knowledge Usability
}

I think $100 \%$ of the information is useful. Even bad information showed something useful about an employee. Constantly using the information to create and modify scorecards on how the company performed is vital to my position.

$$
\begin{aligned}
& \text { Cynthia Emerine, President } \\
& \text { United Capital Mortgage Company }
\end{aligned}
$$

For OMI the information that is most beneficial is the information that comes across my desk every day. Finance reports are reviewed every month. Updates are looked at each week. All operations within the company are reviewed one to two times a week with HQ staff and field directors.

Don Evans, President and CEO

Operations Management International

I estimate $95 \%$ of the information that I receive is useful. However, the problem is not getting rid of the junk; it is finding the time to read everything that would be useful to know.

Debbie Colia, Vice President, HR Qwest

The majority of information that comes across my desk is very useful to me. I get monthly and daily views of graphs and information about how our products are doing and how they rank in our industry.

Ray Cunningham, President and COO

Invesco Funds Group

In the accounting profession, all information is useful at one point or another. An unorganized accountant will never last in any company. When one is dealing with internal control, auditing, etc., there is no time to be searching for lost papers and reports.

\author{
Dennis Kragh, Controller
}

Adam's Mark Hotel

\section{Table 10: Negative Responses to Knowledge Usability}

All of the information that comes across my desk is screened before it comes to me by my secretaries. Even with this screening I only find $5 \%$ of the information that I receive useful in the near future.

$$
\begin{aligned}
& \text { John Ikard, President } \\
& 1^{\text {st }} \text { Bank }
\end{aligned}
$$

$10 \%$ ! I receive a lot of information but most of it does not pertain to my responsibilities.

$$
\begin{aligned}
& \text { Mark Palmer, Senior Vice President } \\
& \text { Salomon Smith Barney }
\end{aligned}
$$

I really only find that about two percent of the information that comes across my desk is useful in the near future. It's basically like your mail at home; there is a lot of junk to sort through.

\author{
Pamela Walker, President \\ Distinctive Home Lending
}

Although about $90 \%$ of the information is used to keep up to date with general operations, only about $20 \%$ of the information is of some direct use in the near future.

\section{Sonja Asper, Senior Vice President} $1^{\text {st }}$ Bank

Because most things have to come through my desk for approval, only $50 \%$ of the information is actually useful. A lot of my time is spent weeding through information that I need and passing the other information to someone else.

Christopher Younger, $\mathrm{COO}$

Expanets, Inc. 
Knowledge management is not an end in itself, but a part of overall business strategy. It provides the information that executives can use to improve decision making. A five-stage paradigm focuses on corporate strategy and direction, emphasizing "the quality of decision making and information use needed to improve overall business performance" (Myburg, 2002). These stages appear in Table 11.

\begin{tabular}{|l|}
\hline \multicolumn{1}{|c|}{ Table 11: Stages in Information Management } \\
\hline Stage 1: Paperwork management \\
Stage 2: Management of corporate automated technologies \\
Stage 3: Management of corporate information resources \\
Stage 4: Business competitor analysis and intelligence \\
Stage 5: Strategic information management \\
\\
\end{tabular}

People do not respond well to big words, 10 step processes, and theories. The feedback system must be evaluated on the value of convincing information that is used in everyday problems. The strategy is to capture and leverage the knowledge asset based on value to the organization culture based on a free-flowing exchange of ideas and information.

Successful knowledge management recognizes the key distinction between information and knowledge: In contrast to information management, knowledge management adds actionable value to information by filtering, synthesizing, and summarizing it to get at the kind of information needed to take action on (Wah, 1999). In the interviews with Rocky Mountain executives, some comments reflected effective filtering within the organization, as shown in Table 12.

\section{Table 12: Effective Filtering within Organizations}

I receive information from throughout the company. Luckily, I have filters to help me weed out less than useful information. As a whole, right now I find all the information that crosses my desk useful.

Gary Dudley, Senior Tax Partner Deloitte and Touche

One hundred percent of the information that comes across my desk is useful because I have the best administrative assistant that filters my mail.

J. F. Trungale, President and CEO

VICORP Restaurants, Inc.

Almost seventy percent of the information that makes it to my desk is useful. I don't have a computer on my desk and calls that come to me are well screened.

Jake Jabs, CEO and Owner

American Furniture Warehouse 
Because the knowledge management process is rather daunting, it does not always guarantee success. Shelfer and Verner identify nine critical indicators of potential failure, as shown in Table 13.

\begin{tabular}{|l|}
\hline \multicolumn{1}{|c|}{ Table 13: Critical Failure Indicators in Knowledge Management } \\
\hline 1. Lack of informed consensus \\
2. Acceptance of the status quo \\
3. Unwarranted trust in the vendor \\
4. Failure to support title business purpose \\
5. A short term, internal, myopic approach \\
6. Paralysis by analysis \\
7. Sabotage by external predators \\
8. Suicide through ignoring project constraints \\
9. Failure to consider business, human, or technology limitations imposed on the project \\
\hline
\end{tabular}

The people, organization, and all activities must operate as one working system. To make this happen all processes must work together.

\subsection{Conclusion}

The preliminary framework for knowledge management comes through an Integrative Model as an attempt to unify and link the elements through which the production of knowledge occurs. To dialogue in this new field, the Integrative Model identifies the individual and organizational inputs and outputs of the knowledge management system. The critical parts of this system are the purpose and method elements of the central integration. The matrices that describe the intentions, audiences, machine tools, and human processes provide a coherent way to visualize the central elements involved in a knowledge management system.

The only distinction between knowledge and information is that knowledge has an inseparable component: cognition. It's that mental faculty by which we acquire and without which we just don't know. And no matter how much information you extract from experts, present in all the right contexts, and try to make actionable, if I don't get it, it will never be knowledge for me. And if it's present before I have my coffee, it might not even make it from jumbled data to information [Pukszta, 1999, p. 32].

The majority of the executives interviewed in the Rocky Mountain region responded very positively based on the usefulness of the knowledge information that crossed their desk. There were a few negative responses and only a few identified effective knowledge-filtering systems within their organization. New knowledge information systems are changing faster than ever and the organization must keep changing and produce change and new information or become extinct.

\section{References}

1. Abell, Angela. "Skills for Knowledge Environments." Information Management Journal, July 2000.

2. Angus, Jeff. "Knowledge Management: Great Concept...But What Is It.” InformationWeek, 16 March 1998.

3. Black, Jason. "Agents in the Field." Internet World, 15 September 2001.

4. Beck, Charles. Management Communication. Prentice-Hall, 1999.

5. Boomer, L. Gary. "Firms Must Learn to Deal with Information Overload. (Boomer's Blueprint)." Accounting Today, 22 October 2001, p. 24.

6. Calo, Jonathan. In "Does Bleeding Edge Software Mark Golden Era of Info Retrieval?” Computing Canada, 10 May 2002. 
7. Clark, Judy and Steven Poruban. “Oil, Gas Industry Makes Advances in Managing Data, Knowledge.” The Oil and Gas Journal, 10 December 2001.

8. Coleman, Christa L. "Knowledge Management in Action." e-Business Advisor, July 2002.

9. Consulting's Next Big Thing." ComputerWorld, 3 January 2000.

10. Davis, Brian. “The Know-How Game.” Engineering, July August 1998, pp. 27-29.

11. de Stricker, Ulla. "Relationships R Us: Climbing up the Value Chain." Information Outlook, November 2000.

12. DeTienne, Kristen Bell and Lisa Ann Jackson. "Knowledge Management: Understanding Theory and Developing Strategy." Competitiveness Review, Winter-Spring 2001.

13. Deveau, Denise. "Does Bleeding Edge Software Mark Golden Era of info Retrieval?" Computing Canada, 10 May 2002.

14. Duffy, Jan. "Knowledge Management and Its Influence on the Records and Information Manager." Information Management Journal, July 2001.

15. Duffy, Jan. "Something Funny is Happening." Information Management Journal, October 2000.

16. Erickson, Rothberg, Carr. "Collaborator Certification: Protecting Knowledge in E-Business Networks." Global Competitiveness, Annual 2001.

17. Erickson, G. Scott and Helen N. Rothberg. "Intellectual Capital and Competitiveness: Guidelines for Policy." Competitiveness Review, Summer-Fall 2000.

18. Friedmann, Ron. "Do you know what you know?” American Lawyer, September 2001.

19. Gore, Chris and Emma Gore. "Knowledge Management: the Way Forward." Total Quality Management, July 1999.

20. Greengard, Samuel. "Taming the Information Glut." Workforce, November 2000.

21. Hansen, Morten T., Nitin Nohria and Thomas Tierney. "What's Your Strategy for Managing Knowledge?" Harvard Business Review, March-April 1999.

22. Hibbard, Justin. "Knowing What We Know." Information Week, 20 October 1997.

23. Mitchell, Ken. "Introducing the Portal." The Public Manager, September 2001.

24. Morrison, Michael and Larissa Mezentseff. "Learning Alliances: A New Dimension of Strategic Alliances." Management Decision, May-June 1997.

25. Myburg, Sue. "Strategic Information Management: Understanding a New Reality." Information Management Journal, January-February 2002.

26. Ojala, Maryd. "Adding External Knowledge to Business Web Sites: Pursuing Internal or External Sources for Information is Not Necessarily an Antagonistic Approach." Online, July-August 2002.

27. Oman, Julie A. "Information Literacy in the Workplace." Informative Outlook, June 2001.

28. Oxbrow, Nigel. "Skills and Competencies to Succeed in a Knowledge Economy." Information Outlook, October 2000.

29. Pemberton, J. Michael. "Knowledge Management (KN) and the Epistemic Tradition." Records Management Quarterly, July 1998.

30. Perna, Janet. "Reinventing How We Do Business." Vital Speeches, 15 July 2001.

31. Porac, Joseph and Mary Ann Glynn. "Cognition and Communication at Work." Academy of Management Review, July 1999.

32. Pukszta, Helen. "Forget Knowledge Management: Back to Information.” Computerworld, 3 May 1999, p. 32.

33. Safdie, Elias and Ray Edwards. "Knowledge Is Power for Government and Business Alike." Government Computer News, 12 January 1998.

34. Serva, Sandy. "Verity: True Value." EContent, July 2002, p. 52.

35. Shelfer, Katherine and June Verner. "A Roadmap for the Successful Implementation of Competitive Intelligence Systems." Information Outlook, July 2001, p. 34.

36. Steinberg, Dan. "Money from Nothing - Use the Net to Exploit the Intangible." Ziff Davis Smart Business for the New Economy, 1 April 2001.

37. Sullivan, Dan. "Machine Translation: Is It Good Enough?" e-Business Advisor, June 2001.

38. Sumner-Smith, Martin. "Practical Knowledge Management for Drug Discovery." Scientific Computing \& Instrumentation, August 2000.

39. Tetenbaum, Toby. "Shifting Paradigms: From Newton to Chaos." Organizational Dynamics, April 1998.

40. Wah, Louisa. "Behind the Buzz." Management Review, April 1999, p. 7.

41. Waltner, Charles. "Knowledge Collaboration -- Antidote for Information Overload -- Online Software Lets Smaller Businesses Cope with Floods of Information.” Information Week, 2 October 2000.

42. Zuckermann, Amy and Hal Buell. “Is the World Ready for Knowledge Management?” Quality Progress, June 1998. 